\title{
No molecular evidence of Hepatitis E infection among patients with HIV in Iran
}

\author{
Hadi Ghaffari ${ }^{1}$, Ahmad Tavakoli ${ }^{1}$, Davod Javanmard ${ }^{1}$, Hamidreza Mollaei $^{2}$, Helya Sadat Mortazavi ${ }^{1}$, \\ Seyed Hamidreza Monavari ${ }^{1 *}$
}

Received: 11 Mar $2017 \quad$ Published: 26 Dec 2017

Copyright $₫$ Iran University of Medical Sciences

Cite this article as: Ghaffari H, Tavakoli A, Javanmard D, Mollaei H, Mortazavi HS, Monavari SH. No molecular evidence of Hepatitis E infection among patients with HIV in Iran. Med J Islam Repub Iran. 2017 (26 Dec);31:135. https://doi.org/10.14196/mjiri.31.135

\section{Brief Communication}

Hepatitis E virus (HEV) typically causes an acute selflimited infection in immunocompetent individuals. However, in recent years, multiple studies have demonstrated that immunocompromised patients such as transplant recipients, hematological patients, and HIV-infected patients are prone to acquiring chronic HEV infection and cirrhosis. In fact, chronic HEV infection in these high-risk groups can be considered as an emerging and clinically significant problem $(1,2)$. In general, HEV RNA-positive serum or stool for 6 months or longer has been suggested as a definition for chronic hepatitis E (3).

According to some previous studies, HIV-infected patients are at higher risk of acquiring chronic HEV infection than individuals without HIV (4). Immunosuppression can result in chronic $\mathrm{HEV}$ infection. So, infection with HIV is considered as one of the probable causes of HEV persistence (5). There are some evidences of acute $\mathrm{HEV}$ infections and persistent carriage of $\mathrm{HEV}$ in patients with HIV (6). Nevertheless, studies on HIV/HEV coinfection in HIV-infected patients are rare in Iran. The aim of present study was to determine the molecular prevalence of HEV infection in Iranian HIV-infected patients.

In total, $86 \mathrm{HIV}-1$ infected patients referred to hospitals of Tehran city (affiliated to Iran University of Medical Sciences, Tehran, Iran) participated in the current study. This work was performed between February 2015 and April 2016. Patients who had received anti-retroviral ther-

Corresponding author: Dr Seyed Hamidreza Monavari, hrmonavari@yahoo.com

1. Department of Virology, School of Medicine, Iran University of Medical Sciences, Tehran, Iran.

2. Department of Microbiology and Virology, School of Medicine, Kerman University of Medical Sciences, Kerman, Iran. apy were excluded from the study. The project was aprroved by the ethics committee of Iran University of Medical Sciences, Tehran, Iran. The patients were informed about the aims of the study, and they signed informed consent before their enrollment. For sampling, approximately five $\mathrm{ml}$ of whole blood was taken from each candidate in an anti- coagulating manner. The plasma was isolated from the samples using centrifuge, and stored at $-70^{\circ} \mathrm{C}$ until use.

HEV-RNA was extracted from plasma samples using High Pure viral Nucleic Acid Kit (Roche Diagnostics, Germany) according to the manufacturer's protocol. cDNA synthesis was carried out using the first strand cDNA synthesis kit by Revert AidcDNA synthesis kit (Thermo Scientific, USA) according to the manufacturer's instruction. Detection of HEV-RNA performed by a TaqMan real-time RT-PCR assay (7). The primers (forward: 5'-GGTGGTTTCTGGGGTGAC-3' and reverse: 5' AGGGGTTGGTTGGATGAA-3') amplify a 70bp fragment in ORF2 of HEV genome. The amplified region is detectable using TaqMan probe (5'-FAM-TGATTCTCAG CCCTTCGC-BHQ-3'). HIV-1 RNA quantification was performed with the COBAS TaqMan (Roche Diagnostics, USA), according to the manufacturer's instructions.

The demographic data of the patients showed that 53 $(61.6 \%)$ of the cases were males and $33(38.4 \%)$ were females. The mean age was $38.23 \pm 9.58$ years, with a wide

$\uparrow$ What is “already known" in this topic:

Previous studies have suggested that patients with HIV infection are at risk for acquiring $\mathrm{HEV}$ infection. Based on the several studies that have been conducted thus far, detection rate of HEV-RNA was low and ranges from 0 to $1.3 \%$ among HIV positive patients.

$\rightarrow$ What this article adds:

Our study has shown that none of the 86 HIV-positive patients tested had HEV RNA in their plasma examined by real-time RT-PCR assay, which was consistent with results of other previous studies. 
range (4-65 years) of age distribution. The mean HIV viral load of all patients with HIV was 32026.75 copies per ml. None of the 86 HIV-positive patients tested had HEVRNA detected in their plasma by real-time RT-PCR assay.

In the recent years, HEV infection has introduced as an emerging infection in immunosuppressed patients worldwide, most notably in resource-limited countries. It has been shown that HEV infection can lead to acute and chronic hepatitis in immunocompromised patients, including in patients with late stage of HIV infection. The presence of HEV-RNA in patient's specimen indicates an ongoing infection (8).

Based on the several studies that have been conducted thus far, the prevalence of IgG against hepatitis E virus among HIV positive cases ranges from 1.5-11.2\% worldwide, while the detection rate of HEV-RNA is low and ranges from 0 to $1.3 \%$ (9). Our study has shown the lack of detectable HEV-RNA in plasma samples obtained from a group of Iranian HIV patients, which was consistent with results of other previous studies (10-17).

Only limited studies carried out on the prevalence of $\mathrm{HEV}$ infection among Iranian HIV-infected patients. Joulaei et al. reported that the overall seroprevalence of hepatitis E among patients infected with HIV was 16.4\% (18). Another study by Ramezani et al. showed that the seroprevalence of HEV was $10 \%$ in HIV patients and no HIV-infected patients had detectable hepatitis E virusRNA (15).

Detection of specific anti-HEV antibodies can help to determine whether the infection was recent; however, these antibodies can persist for months or even years after acute infection, without detection of any HEV-RNA. For this reason, the rate of HEV seroprevalence is usually significantly higher than HEV-RNA prevalence. On the other hand, the results of serological assays may be negative despite ongoing or occult HEV infection (19); hence, in patients with HIV infection, PCR assay for HEV-RNA should be considered.

In recent years, molecular assays such as real-time PCR analysis have been applied for viral genomic RNA detection and diagnosis of $\mathrm{HEV}$ infection $(20,21)$. It has demonstrated that the presence of HEV-RNA in fecal or serum specimens is the most reliable marker for diagnosis of HEV infection (22-24). Real-time PCR provides a rapid, sensitive, and robust method for measuring HEV-RNA that has replaced the traditional serological assays as the gold standard for diagnosis of HEV infection (25); however, duration of HEV viremia in primary infections is short (10-30 days after the onset of symptoms). So, detection of HEV RNA is difficult for diagnosis in clinical practice within the proper time. Nevertheless, it should be noted that our small sample size can be considered as a limitation of the study. On the other hand, some previous studies have reported an increased seroprevalence of HEV in immunocompromised patients with HIV infection. Therefore, further case-control studies with serology approach and larger sample size, alongside detection of HEV RNA in both blood and stool samples are recommended for future research.

\section{Acknowledgment}

This study was funded by Iran University of Medical Sciences, Grant no. 27004 .

\section{Conflict of Interests}

The authors declare that they have no competing interests.

\section{References}

1. Renou C, Lafeuillade A, Cadranel JF, Pavio N, Pariente A, Allègre $\mathrm{T}$, et al. Hepatitis $\mathrm{E}$ virus in HIV-infected patients. Aids. 2010;24(10):1493-9.

2. Péron JM. Hepatitis E Virus Infection and Cirrhosis of the Liver. Gastroenterol Hepatol. 2016;12(9):565.

3. Behrendt P, Steinmann E, Manns MP, Wedemeyer H. The impact of hepatitis E in the liver transplant setting. J Hepatol. 2014;61(6):141829.

4. Crum-Cianflone NF, Curry J, Drobeniuc J, Weintrob A, Landrum M, Ganesan A, et al. Hepatitis E Virus Infection in HIV-infected Persons. Emerg Infect Dis. 2012;18(3):502.

5. Singh GKJ, Ijaz S, Rockwood N, Farnworth SP, Devitt E, Atkins M, et al. Chronic Hepatitis E as a cause for cryptogenic cirrhosis in HIV. J Infect. 2013;66(1):103-6.

6. Sellier P, Mazeron MC, Tesse S, Badsi E, Evans J, Magnier JD, et al. Hepatitis E virus infection in HIV-infected patients with elevated serum transaminases levels. Virol J. 2011;8:171.

7. Jothikumar N, Cromeans TL, Robertson BH, Meng X, Hill VR. A broadly reactive one-step real-time RT-PCR assay for rapid and sensitive detection of hepatitis $\mathrm{E}$ virus. J Virol Methods. 2006;131(1):65-71.

8. Kamar N, Rostaing L, Izopet J, editors. Hepatitis E virus infection in immunosuppressed patients: natural history and therapy. Semin Liver Dis; 2013.

9. Kamar N, Dalton HR, Abravanel F, Izopet J. Hepatitis E virus infection. Clin Microbiol Rev. 2014;27(1):116-38.

10. Pischke S, Schwarze-Zander C, Bremer B, Lehmann P, Wiegand $\mathrm{SB}$, Gisa A, et al. Hepatitis $\mathrm{E}$ virus seroprevalence rate in HIVinfected patients in Germany: a comparison of two commercial assays. Intervirology. 2015;58(5):283-7.

11. Nouhin J, Barennes H, Madec Y, Prak S, Hou SV, Kerleguer A, et al. Low frequency of acute hepatitis E virus (HEV) infections but high past HEV exposure in subjects from Cambodia with mild liver enzyme elevations, unexplained fever or immunodeficiency due to HIV-1 infection. J Clin Virol. 2015;71:22-7.

12. Bradley-Stewart A, Jesudason N, Michie K, Winter A, Gunson R. Hepatitis E in Scotland: assessment of HEV infection in two high-risk patient groups with elevated liver enzymes. J Clin Virol. 2015;63:367.

13. Sherman KE, Terrault N, Barin B, Rouster SD, Shata MT. Hepatitis $\mathrm{E}$ infection in HIV-infected liver and kidney transplant candidates. J Viral Hepat. 2014;21(8):e74-e7.

14. Hassing R, van der Eijk A, Lopes VB, Snijdewind I, de Man R, Pas $\mathrm{S}$, et al. Hepatitis $\mathrm{E}$ prevalence among HIV infected patients with elevated liver enzymes in the Netherlands. J Clin Virol. 2014;60(4):408-10.

15. Ramezani A, Velayati AA, Khorami-Sarvestani S, Eslamifar A, Mohraz M, Banifazl M, et al. Hepatitis E virus infection in patients infected with human immunodeficiency virus in an endemic area in Iran. Int J STD AIDS. 2013;24(10):769-74

16. Feldt T, Sarfo FS, Zoufaly A, Phillips RO, Burchard G, van Lunzen $\mathrm{J}$, et al. Hepatitis E virus infections in HIV-infected patients in Ghana and Cameroon. J Clin Virol. 2013;58(1):18-23.

17. Maylin S, Stephan R, Molina J-M, Peraldi M-N, Scieux C, Nicand E, et al. Prevalence of antibodies and RNA genome of hepatitis E virus in a cohort of French immunocompromised. J Clin Virol. 2012;53(4):346-9.

18. Joulaei H, Rudgari O, Motazedian N, Gorji-Makhsous S. Hepatitis $\mathrm{E}$ virus seroprevalence in HIV positive individuals in Shiraz, Southern Iran. Iran J Microbiol. 2015;7(2):103.

19. Rivero-Juarez A, Martinez-Dueñas L, Martinez-Peinado A, Camacho A, Cifuentes C, Gordon A, et al. Absence of occult Hepatitis E virus infection among HIV immunosuppressed patients. J Infect. 2015;70(6):680. 
20. Meng J, Dubreuil P, Pillot J. A new PCR-based seroneutralization assay in cell culture for diagnosis of hepatitis E. J Clin Microbiol. 1997;35(6):1373-7.

21. Mérens A, Guérin PJ, Guthmann J-P, Nicand E. Outbreak of hepatitis E virus infection in Darfur, Sudan: effectiveness of real-time reverse transcription-PCR analysis of dried blood spots. J Clin Microbiol. 2009;47(6):1931-3.

22. Gyarmati P, Mohammed N, Norder H, Blomberg J, Belák S, Widén F. Universal detection of hepatitis E virus by two real-time PCR assays: TaqMan ${ }^{\circledR}$ and Primer-Probe Energy Transfer. J Virol Methods. 2007;146(1):226-35

23. Zhao C, Li Z, Yan B, Harrison TJ, Guo X, Zhang F, et al. Comparison of real-time fluorescent RT-PCR and conventional RTPCR for the detection of hepatitis E virus genotypes prevalent in China. J Med Virol. 2007;79(12):1966-73.

24. Zhao ZY, Ruan B, Shao H, Chen ZJ, Liu SL. Detection of hepatitis $E$ virus RNA in sera of patients with hepatitis $E$ by polymerase chain reaction. Hepatobiliary Pancreat Dis Int. 2007;6(1):38-42.

25. Mushahwar IK. Hepatitis E virus: molecular virology, clinical features, diagnosis, transmission, epidemiology, and prevention. J Med Virol. 2008;80(4):646-58 